\title{
ASSUMPTIONS AND SIMULATION OF PASSENGER BEHAVIOUR ON RAIL PLATFORMS
}

\author{
L. D'ACIERNO, M. BOTTE \& B. MONTELLA \\ Department of Civil, Architectural and Environmental Engineering, Federico II University of Naples, Italy
}

\begin{abstract}
Current techniques of travel demand management are based on the simulation of users' reactions to implement strategies. Indeed, the correct modelling of user behaviour may be considered important for managing public transport systems. Especially in high-density contexts, performance of the masstransit system may represent one of the main tools of decision-makers for affecting users' choices. In this article, we focus on the behaviour of users waiting on rail/metro platforms, analysing boarding priorities when a train arrives based on the traditional First In-First Out (FIFO) approach and comparing it with Random In-First Out (RIFO) behaviour. The approaches are then applied in the case of a real metro line operating under different congestion levels.

Keywords: capacity constraints, FIFO approach, microsimulation approach, passenger behaviour, public transport management, rail passenger systems, RIFO approach, traffic assignment models.
\end{abstract}

\section{INTRODUCTION}

Performance of the public transport system may be considered a useful tool for managing travel demand. Indeed, since each user tends to choose mobility alternatives (in terms of vehicle ownership, departure time, transport mode and route choices) which maximize his/her own utility (according to the assumptions of rational decision-makers proposed by Ben Akiva and Lerman [1]), it is necessary to adopt push-and-pull policies (see, for instance, Eriksson et al. [2], Habibian and Kermanshah [3], Meyer [4]) in order to steer user behaviour towards an optimal condition of transportation system use.

Especially in high-density contexts, where there are numerous public transport modes, it is necessary to organize services according to a hierarchical framework based, for instance, on the use of exclusive lane systems (such as trains, metros, trams and expressed buses) as the high-performance backbone of public transport mobility, and shared lane systems (such as buses and trolleybuses) as feeder services for increasing the geographical coverage of public transport (see, for instance, Chien and Schonfeld [5], Kuan et al. [6], Shrivastav and Dhingra [7]). However, rail-based systems, albeit providing high-quality services, are very vulnerable to system breakdowns, as shown by D'Acierno et al. [8]. Hence, many authors have focused their research on improving service quality (Abenoza et al. [9], dell'Olio et al. [10], de Ona and de Ona [11]), reducing impacts on users in the event of system failure (Consilvio et al. [12], Pereira et al. [13]) and on implementing rescheduling and dispatching techniques to reduce failure effects (Corman and Meng [14], Gao et al. [15], Zhan et al. [16]). In particular, rescheduling and dispatching may be considered aspects of managing and monitoring rail operations in order to ensure the smooth running of services and re-establish ordinary conditions in response to any kind of system failure. Obviously, the greater the severity of the failure, the greater the impact of corrective measures to be adopted.

However, failures of rail/metro/tram systems may be classified into disturbances and disruptions (Cacchiani et al. [17]). The former term refers to events that cause small alterations to ordinary operations, while the latter indicates more serious incidents which can lead to the cancellation of train runs or even the interruption of the whole service. For example, 
Dollevoet et al. [18] deal with the problem of connection and rerouting of passengers in the case of a delay occurrence, while more severe perturbations are tackled by Corman et al. [19] and Ghaemi et al. [20].

In this context, each intervention strategy, both for planning the service and mitigating the negative impact on users, may be formulated as a bilevel multidimensional constraint optimization problem (see Montella et al. [21]), that is:

$$
\hat{\boldsymbol{y}}=\underset{\boldsymbol{y} \in \mathbf{S}_{\boldsymbol{y}}}{\arg \min } Z\left(\boldsymbol{y}, \boldsymbol{f}^{*}\right)
$$

subject to:

$$
\begin{gathered}
f^{*}=\Gamma\left(f^{*}, y\right) \\
\lambda\left(y, f^{*}\right) \leq B
\end{gathered}
$$

where $\boldsymbol{y}$ is the vector of decisional variables (i.e. parameters to be optimized), $\hat{\boldsymbol{y}}$ is the optimal value of $\boldsymbol{y} ; \boldsymbol{S}_{\boldsymbol{y}}$ is the feasibility set of $\boldsymbol{y}, Z(\cdot)$ is the objective function to be minimized, $\boldsymbol{f}^{*}$ is the vector of descriptive variables (i.e. effects on user choices of design variable values), $\boldsymbol{\Gamma}(\cdot)$ is the assignment (or simulation) function, $\lambda(\cdot)$ is the budget function and $B$ is the budget constraint. Details on objective function formulation may be found in D'Acierno et al. [22]. Likewise, the use of optimization techniques for improving public transport may be found in Botte et al. [23], Cadarso and Marìn [24], Lee and Vuchic [25] and Marìn and Garcìa-Ròdenas [26].

Equation (2) expresses the recursive dependence between user flows and transportation system costs. According to rational decision-maker assumptions, users tend to choose alternatives with the lowest costs (for instance, the route of minimum cost). Moreover, the cost of an alternative (for instance, travel time) depends on the number of users who choose that alternative (i.e. the dwell time of a train in a station depends on the number of passengers boarding and alighting at the station). The problem may be expressed in terms of a fixedpoint problem in the case of stationary hypotheses or in terms of similar analytical formulations. However, this problem has been extensively analysed elsewhere (see, for instance, Cantarella [27], D’Acierno et al. [28], Nguyen et al. [29], Nuzzolo et al. [30]).

Relation (3) represents the budget constraint which may be expressed in terms of both economic resources (i.e. the maximum amount of money to be used) and physical resources (i.e. the maximum number of facilities to be used).

According to the above-mentioned approach, correct modelling of user behaviour is fundamental in order to select the most appropriate alternative project or intervention policy by simulating the behavioural reaction of users beforehand. Hence, in this article, we explore some assumptions on boarding priorities when a train arrives in order to provide a simulation model (generally described by eqn (2)) which best imitates user choices.

This article is organized as follows: Section 2 formulates and describes the assumptions on boarding priorities; Section 3 applies the approaches considered in the case of a real metro line; finally, conclusions and research prospects are summarized in Section 4.

\section{ASSUMPTIONS ON USER BEHAVIOUR}

Although there are numerous models for simulating the behaviour of passengers on rail/metro platforms (see, for instance, D'Acierno et al. [31], Kunimatsu et al. [32]), most of them are based on a First In-First Out (FIFO) approach. Hence, our proposal consists in proposing a 
different approach, termed Random In-First Out (RIFO), and comparing it with the traditional one in terms of rail system performance. We adopt the following assumptions common to the two approaches:

- Platforms are able to accommodate all incoming, waiting and outgoing passengers.

- The platform is uniquely determined once the run and station have been fixed (i.e. trains travelling in the same direction always stop at the same platform in a station).

- The dwell time of trains is constant (once the run, station and platform have been fixed) and is independent of alighting and boarding flows.

- There is no interaction on the platform between alighting, boarding and waiting passengers.

- Trains have a fixed capacity which means that the number of boarding passengers may be at most equal to the residual capacity.

- Passengers are uniformly distributed in the trains. This means that all coaches of the same train have the same density and the residual capacity is equally distributed among carriages. Moreover, an increase or a decrease in the passenger number inside the train is equally distributed among coaches.

- There is no interaction in the train between alighting, boarding and on-board passengers, except in the definition of residual capacity. This means that a different position (i.e. left or right) of platforms in subsequent stations does not affect the fluidity of passenger movements inside the coaches.

Analytically, both approaches are based on the following equations:

$$
\begin{gathered}
\operatorname{ar}_{\Delta t}^{s, p, d}=\int_{\Delta t} f_{\text {in }}^{s, p, d}(\tau) \cdot d \tau \\
\mathrm{wp}_{r}^{s, p, d}=\sum_{\Delta t=0}^{t(r, s, p)} \mathrm{ar}_{\Delta t}^{s, p, d}-\sum_{i=1}^{r-1} \mathrm{bf}_{i}^{s, p, d} \\
\mathrm{WP}_{r}^{s, p}=\sum_{d} \mathrm{wp}_{r}^{s, p, d} \\
\mathrm{RC}_{r}^{s, p}=\mathrm{CAP}_{r}-\sum_{i=1}^{s-1} \sum_{d} \mathrm{bf}_{r}^{i, p, d}+\sum_{j=1}^{s} \mathrm{af}_{r}^{j, p} \\
\mathrm{BF}_{r}^{s, p}=\sum_{d} \mathrm{bf}_{r}^{s, p, d} \\
\mathrm{BF}_{r}^{s, p}= \begin{cases}\mathrm{WP}_{r}^{s, p} & \text { if } \mathrm{WP}_{r}^{s, p} \leq \mathrm{RC}_{r}^{s, p} \\
\mathrm{RC}_{r}^{s, p} & \text { if } \mathrm{WP}_{r}^{s, p}>\mathrm{RC}_{r}^{s, p}\end{cases}
\end{gathered}
$$

where $p$ is the generic platform which, according to the above assumptions, depends on run $r$ and station $s ; f_{\text {in }}^{s, p, d}(\tau)$ is the incoming passenger flow on platform $p$ of station $s$, heading for destination $d$, in the time instant $t ; \Delta t$ is the generic time interval; $\operatorname{ar}_{\Delta t}^{s, p, d}$ is the incoming passenger flow (arrival rate) on platform $p$ of station $s$, heading for destination $d$, during the 
time interval $\Delta t ; \mathrm{bf}_{r}^{s, p, d}$ is the boarding passenger flow on run $r$ on platform $p$ of station $s$, heading for destination $d$; $t$ is the time interval when run $r$ arrives on platform $p$ of station $s$; $\mathrm{wp}_{r}^{s, p, d}$ is the waiting passenger flow on platform $p$ of station $s$, bound for destination $d$, when run $r$ arrives; $\mathrm{WP}_{r}^{s, p}$ is the waiting passenger flow on platform $p$ of station $s$, bound for all destinations, when run $r$ arrives; $\mathrm{af}_{r}^{s, p}$ is the alighting passenger flow from run $r$ on platform $p$ of station $s ; \mathrm{CAP}_{r}$ is the rail convoy capacity of run $r ; \mathrm{RC}_{r}^{s, p}$ is the residual capacity of run $r$ when the train arrives at platform $p$ of station $s ; \mathrm{BF}_{r}^{s, p}$ is the boarding passenger flow on run $r$ on platform $p$ of station $s$, bound for all destinations.

Equation (4) expresses the arrival flow at a platform as the sum of incoming passengers; eqn (5) provides waiting flows as the difference between arrival and boarding flows; eqn (6) expresses the waiting flow bound for all destinations as the sum of waiting flows heading for each destination $d$; eqn (7) provides the residual capacity as the rail convoy capacity minus the boarding flow plus the alighting flow; eqn (8) expresses the boarding flow to all destinations as the sum of boarding flows to each destination $d$; finally, eqn (9) calculates the significance of capacity constraints by expressing boarding flows as a function of waiting flows and residual capacities. In particular, the last equation simulates that if the waiting flow is at most equal to the residual capacity, all passengers are able to board the first arriving train; otherwise only some are able to board while the remaining passengers have to wait for the following trains.

The traditional approach for simulating queue behaviour at platforms is based on the assumption that the boarding order is related to the arrival order according to a FIFO rule. This means that a passenger may board a train only after all passengers arriving before him/ her have boarded the train. Figure 1 provides a description of the FIFO rule in boarding behaviour. In terms of equations, the FIFO approach may be formulated by considering the following equations:

$$
\begin{gathered}
x_{r}^{s, p}: \int_{0}^{x_{r}^{s, p}} \sum_{d} f_{\mathrm{in}}^{s, p, d}(\tau) \cdot d \tau-\sum_{i=1}^{r-1} \sum_{d} \mathrm{bf}_{i}^{s, p, d}=\mathrm{RC}_{r}^{s, p} \\
\mathrm{bf}_{r}^{s, p, d}=\int_{0}^{x_{r}^{s, p}} f_{\mathrm{in}}^{s, p, d}(\tau) \cdot d \tau-\sum_{i=1}^{r-1} \mathrm{bf}_{i}^{s, p, d}
\end{gathered}
$$

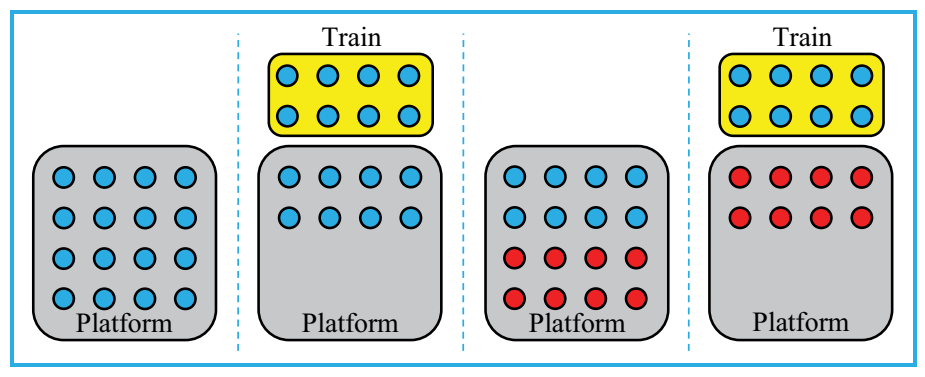

Figure 1: Description of the First In-First Out (FIFO) approach. 
where, in over-saturated conditions (i.e. when residual capacity is lower than the number of passengers waiting), it is necessary to calculate the time instant $x_{r}^{s, p}$ which satisfies eqn (10) and allows the boarding flow to be calculated by means of eqn (11).

The proposed approach to queue behaviour is based on the assumption that passengers waiting on the platform tend to move around by mixing with respect to their arrival order. In particular, in the current RIFO approach, we propose a maximum degree of mixing which means that passengers are uniformly distributed on the platform with respect to the destination and arrival rates. Figure 2 provides a graphical description of the proposed RIFO approach.

Analytically, the RIFO approach may be formulated by the following equations:

$$
\begin{gathered}
\alpha_{r}^{s, p}=\left\{\begin{array}{cc}
1 & \text { if } \mathrm{WP}_{r}^{s, p} \leq \mathrm{RC}_{r}^{s, p} \\
\mathrm{RC}_{r}^{s, p} / \mathrm{WP}_{r}^{s, p} & \text { if } \mathrm{WP}_{r}^{s, p}>\mathrm{RC}_{r}^{s, p}
\end{array}\right. \\
\mathrm{bf}_{r}^{s, p, d}=\alpha_{r}^{s, p, d} \cdot \mathrm{Wp}_{r}^{s, p, d}
\end{gathered}
$$

where it is necessary to calculate the rate $\alpha_{r}^{s, p}$ which satisfies eqn (12) and allows boarding flow to be calculated by means of eqn (13).

In the case of under-saturated conditions (i.e. when residual capacity exceeds the number of passengers waiting), $x_{r}^{s, p}$ is equal to the arrival time of run $r$ (i.e. time $t$ ) and $\alpha_{r}^{s, p}$ is equal to 1. In particular, since all passengers are able to board the first arriving train, both approaches provide the same result.

\section{APPLICATION OF THE PROPOSED ASSUMPTIONS}

The proposed assumptions were applied in the case of line 1 of the Naples metro system in the south of Italy. The metro line in question, shown in Fig. 3, consists of 18 stations and connects the hinterland (i.e. Piscinola and Chiaiano) with the city centre (i.e. Municipio and Garibaldi). The main features of the line are shown in Table 1.

The application consisted in analysing the simulation of the two passenger behaviours (i.e. FIFO and RIFO) in the case of different travel demand levels. In particular, each travel demand level was obtained by multiplying uniformly the average working-day demand by 15 values between 0.2 (i.e. 20\%) and 3.0 (i.e. 300\%). Obviously, in the case of a multiplier equal to 1.0 (i.e. $100 \%$ ), the demand level is exactly the average working-day demand.

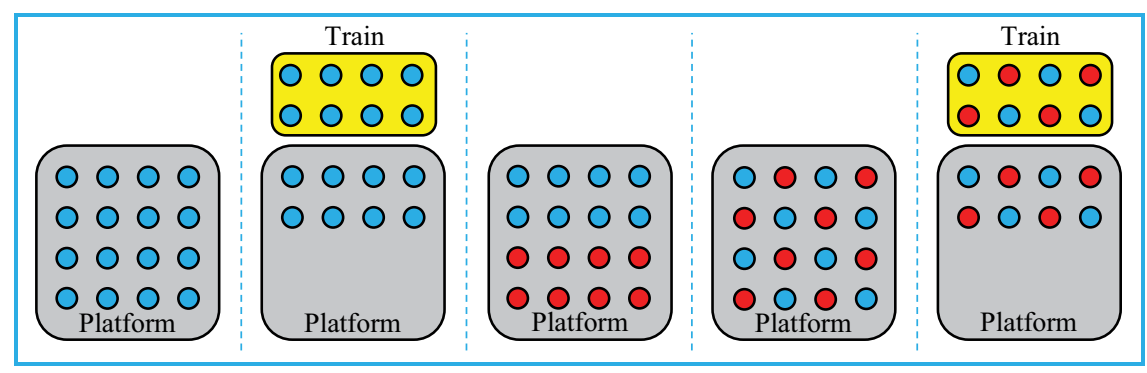

Figure 2: Description of the Random In-First Out (RIFO) approach. 


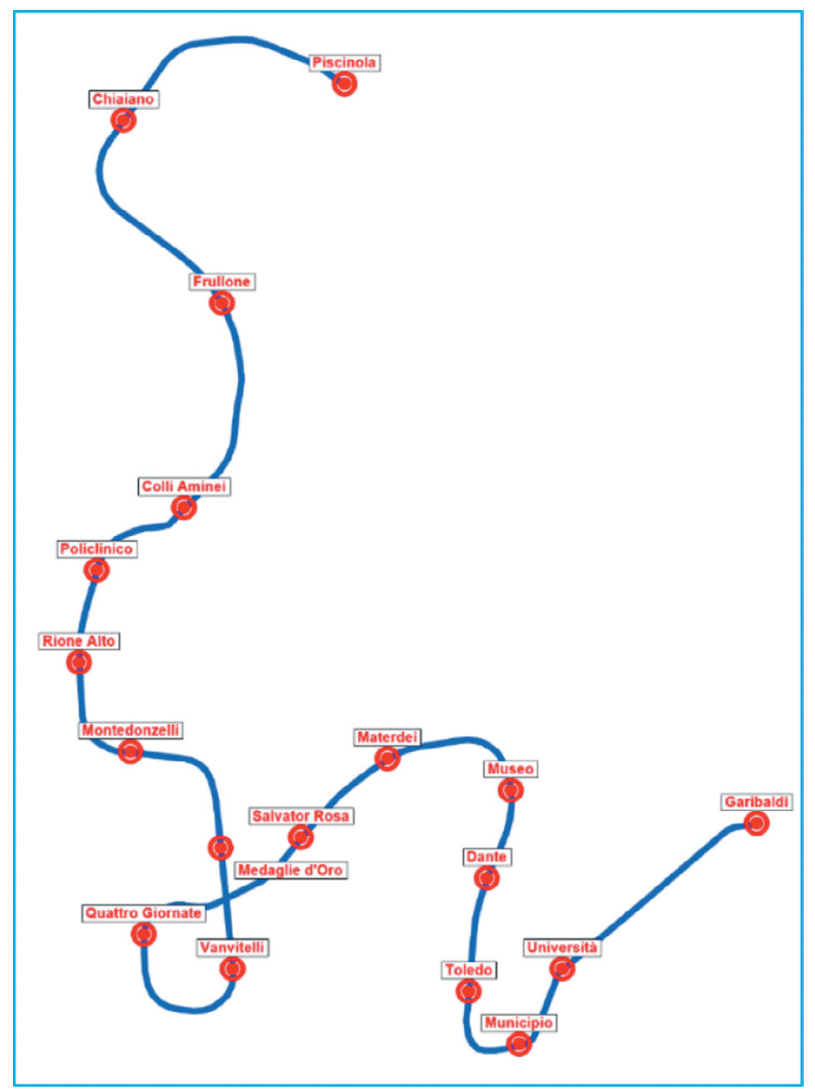

Figure 3: Line 1 of the Naples metro system.

Table 1: Main features of line 1.

\begin{tabular}{lrllrl}
\hline Number of stations & 18 & & Headway & 8.0 & Minimum \\
Working day runs & 241 & & (min) & 20.0 & Maximum \\
Train capacity & 864 & Pax/train & & 8.35 & Average \\
Line length & 18.791 & Outward trip & First run & $06: 00$ & At Piscinola \\
& & & & station \\
& 18.616 & Return trip & Last run & $23: 02$ & At Garibaldi \\
& & & & station \\
\hline
\end{tabular}

Total On-Board Time (TOBT) represents the total time spent on the train by passengers during their trip. It may be calculated as

$$
\mathrm{TOBT}=\sum_{l} \sum_{r} \mathrm{att}_{l}^{r} \cdot \mathrm{ufb}_{l}^{r}
$$

where att $_{l}^{r}$ is the average travel time of run $r$ on link $l$; ufb ${ }_{l}^{r}$ is the number of passengers who are on board run $r$ on link $l$. 
Likewise, Total Waiting Time (TWT) represents the total time spent by passengers on the platform waiting for a train. It may be calculated as:

$$
\mathrm{TWT}=\sum_{s} \sum_{p} \sum_{r} \mathrm{tw}_{s, p}^{r} \cdot \mathrm{ufw}_{s, p}^{r}
$$

where $\mathrm{tw}_{s, p}^{r}$ is the average waiting time between run $r$ and run $(r-1)$ at station $s$ on platform $p$; $\mathrm{ufw}_{s, p}^{r}$ is the number of passengers waiting for run $r$ at station $s$ on platform $p$.

According to D'Acierno et al. [22], two objective functions may be adopted:

- The first objective function, indicated as OF1, expresses the total time spent by passengers on the metro system, that is:

$$
\mathrm{OF} 1=\mathrm{TOBT}+\beta_{w} \cdot \mathrm{TWT}
$$

where $\beta_{w}$ is a parameter that describes user perception of the time spent waiting for trains with respect to the perception of the time spent on board the train (which is assumed as unitary).

- The second objective function, indicated as OF2, expresses the total cost supported by passengers and the mass transit agency, that is:

$$
\mathrm{OF} 2=\mathrm{UTC}+\mathrm{MTAC}
$$

with

$$
\begin{gathered}
\mathrm{UTC}=\beta_{\mathrm{VOT}} \cdot\left(\mathrm{TOBT}+\beta_{w} \cdot \mathrm{TWT}\right)+\mathrm{TTC} \\
\text { MTAC }=\mathrm{TOC}-\mathrm{TR} \\
\mathrm{TOC}=\sum_{r} L_{r} \cdot c_{r} \cdot \mathrm{ntu}_{r}
\end{gathered}
$$

where UTC is the user total cost; MTAC is the mass-transit agency cost; $\beta_{\text {voT }}$ is a parameter which expresses the monetary value of time; TTC is the total ticket cost, that is the total expenditure incurred by passengers for the purchase of tickets; TOC is the total operational cost, that is the total expenditure incurred by the mass-transit agency for metro operations; TR is ticket revenue; $L_{r}$ is the length covered by run $r ; c_{r}$ is the cost per kilometre and per traction unit used for run $r$; $\mathrm{ntu}_{r}$ is the number of traction units used for run $r$.

Table 2: Parameter values.

\begin{tabular}{ll}
\hline Parameter & Value \\
\hline$\beta_{\mathrm{w}}$ & 2.5 \\
$\beta_{\mathrm{vOT}}$ & $€ 5.0 / \mathrm{h}$ \\
$\mathrm{c}_{\mathrm{r}}$ & $€ 18.17 /$ traction unit-km \\
ntu $_{r}$ & 2 traction units/train \\
\hline
\end{tabular}


It is worth pointing out that, since the term TTC is always equal to the term TR, in the definition of OF2 they cancel each other out and we may therefore neglect their calculation. However, parameter values adopted in the application are summarized in Table 2 and numerical results are shown in Tables 3 and 4, and in Figs 4 and 5.

In Fig. $4 \mathrm{a}$, the grey line represents the proportional increase (according to the value of multipliers) in travel demand. The numerical results show that in the case of multipliers lower than $100 \%$ (which represents the current demand) all the demand is assigned (i.e. all passengers are able to board a train) and the two approaches provide the same results.

However, the reduction in assigned travel demand does not have a discontinuity or a threshold because the increase in passengers tends to fill the non-saturated trains. Also in this case, the two approaches provide similar results.

Figure $4 \mathrm{~b}$ represents the unassigned demand. In this case, the grey line represents the increase in passengers with respect to the current condition. For values lower than $100 \%$, it is null because there is no surplus in demand, and the two approaches assign all passengers and provide the same results. In the case of values higher than $100 \%$, passengers tend to fill convoys that are not perfectly full (i.e. with non-null residual capacity). Values then tend to develop an asymptotic behaviour with respect to the grey line where the slant asymptote is shifted as a function of the residual capacity in the case of $100 \%$ (i.e. current travel demand).

In Fig. 4c, the grey line represents the increase in TOBT on the assumption of absence of capacity constraints (i.e. all demand may be assigned and all passengers are able to board the first arriving train). The two approaches have a performance similar to the assigned travel demand since running times of convoys are assumed as constant (i.e. we neglected the increase in dwell times due to different values of travel demand whose details may be found in D'Acierno et al. [33]).

Table 3: Simulation results in the case of FIFO approach.

\begin{tabular}{llllllr}
\hline $\begin{array}{l}\text { Travel } \\
\text { demand } \\
\text { multiplier }\end{array}$ & $\begin{array}{l}\text { Assigned } \\
\text { travel } \\
\text { demand } \\
\text { (pax/day) }\end{array}$ & $\begin{array}{l}\text { Unsatisfied } \\
\text { travel } \\
\text { demand } \\
\text { (pax/day) }\end{array}$ & $\begin{array}{l}\text { Total } \\
\text { on-board } \\
\text { time } \\
\text { (h/day) }\end{array}$ & $\begin{array}{l}\text { Total } \\
\text { waiting } \\
\text { time } \\
\text { (h/day) }\end{array}$ & $\begin{array}{l}\text { Objective } \\
\text { function } \\
\text { no. 1 } \\
\text { (h/day) }\end{array}$ & $\begin{array}{l}\text { Objective } \\
\text { function } \\
\text { no. 2 } \\
\text { (€/day) }\end{array}$ \\
\hline 0.2 & 42,411 & - & 9,205 & 3,006 & 16,719 & 228,817 \\
0.4 & 84,823 & - & 18,410 & 6,012 & 33,439 & 312,413 \\
0.6 & 127,234 & - & 27,615 & 9,017 & 50,158 & 396,010 \\
0.8 & 169,645 & - & 36,820 & 12,023 & 66,877 & 479,607 \\
1.0 & 212,056 & - & 46,025 & 15,055 & 83,661 & 563,526 \\
1.2 & 253,898 & 569 & 55,130 & 26,249 & 120,751 & 748,975 \\
1.4 & 291,860 & 5,018 & 63,580 & 90,230 & 289,156 & $1,590,999$ \\
1.6 & 319,785 & 19,505 & 69,916 & 160,021 & 469,968 & $2,495,058$ \\
1.8 & 347,807 & 33,894 & 75,874 & 249,388 & 699,344 & $3,641,942$ \\
2.0 & 372,765 & 51,347 & 81,138 & 393,097 & $1,063,880$ & $5,464,620$ \\
2.2 & 386,184 & 80,339 & 84,070 & 476,644 & $1,275,680$ & $6,523,618$ \\
2.4 & 397,988 & 110,947 & 86,290 & 550,163 & $1,461,697$ & $7,453,704$ \\
2.6 & 407,364 & 143,982 & 87,848 & 601,872 & $1,592,528$ & $8,107,858$ \\
2.8 & 417,561 & 176,197 & 89,118 & 721,169 & $1,892,040$ & $9,605,418$ \\
3.0 & 427,658 & 208,511 & 90,217 & 817,240 & $2,133,319$ & $10,811,812$ \\
\hline
\end{tabular}


Table 4: Simulation results in the case of RIFO approach.

\begin{tabular}{lllllll}
\hline $\begin{array}{l}\text { Travel } \\
\text { demand } \\
\text { multiplier }\end{array}$ & $\begin{array}{l}\text { Assigned } \\
\text { travel } \\
\text { demand } \\
\text { (pax/day) }\end{array}$ & $\begin{array}{l}\text { Unsatisfied } \\
\text { travel } \\
\text { demand } \\
\text { (pax/day) }\end{array}$ & $\begin{array}{l}\text { Total } \\
\text { on-board } \\
\text { time } \\
\text { (h/day) }\end{array}$ & $\begin{array}{l}\text { Total } \\
\text { waiting } \\
\text { time } \\
\text { (h/day) }\end{array}$ & $\begin{array}{l}\text { Objective } \\
\text { function } \\
\text { no. } 1 \\
\text { (h/day) }\end{array}$ & $\begin{array}{l}\text { Objective } \\
\text { function } \\
\text { no. } 2 \\
\text { (€/day) }\end{array}$ \\
\hline 0.2 & 42,411 & - & 9,205 & 3,006 & 16,719 & 228,817 \\
0.4 & 84,823 & - & 18,410 & 6,012 & 33,439 & 312,413 \\
0.6 & 127,234 & - & 27,615 & 9,017 & 50,158 & 396,010 \\
0.8 & 169,645 & - & 36,820 & 12,023 & 66,877 & 479,607 \\
1.0 & 212,056 & - & 46,025 & 15,055 & 83,661 & 563,526 \\
1.2 & 253,898 & 569 & 55,130 & 26,111 & 120,408 & 747,260 \\
1.4 & 291,860 & 5,018 & 63,580 & 85,311 & 276,859 & $1,529,515$ \\
1.6 & 319,999 & 19,291 & 69,911 & 141,934 & 424,747 & $2,268,954$ \\
1.8 & 347,874 & 33,828 & 75,873 & 225,084 & 638,584 & $3,338,141$ \\
2.0 & 372,883 & 51,230 & 81,100 & 352,270 & 961,774 & $4,954,089$ \\
2.2 & 386,325 & 80,198 & 84,009 & 412,265 & $1,114,671$ & $5,718,575$ \\
2.4 & 397,631 & 111,304 & 86,173 & 464,205 & $1,246,686$ & $6,378,651$ \\
2.6 & 407,162 & 144,184 & 87,739 & 507,172 & $1,355,669$ & $6,923,563$ \\
2.8 & 416,054 & 177,704 & 88,898 & 573,993 & $1,523,882$ & $7,764,630$ \\
3.0 & 423,831 & 212,337 & 89,862 & 619,329 & $1,638,185$ & $8,336,145$ \\
\hline
\end{tabular}

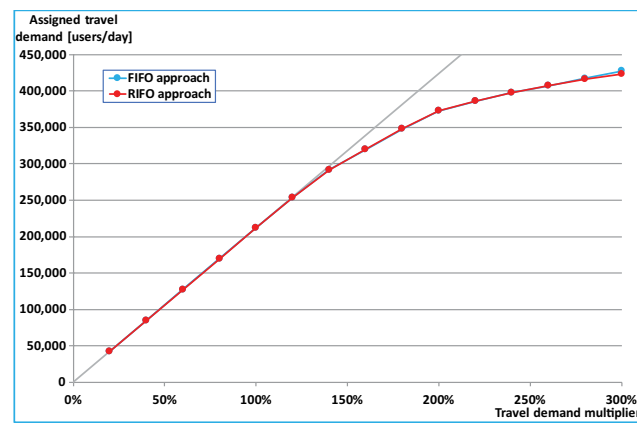

(a)

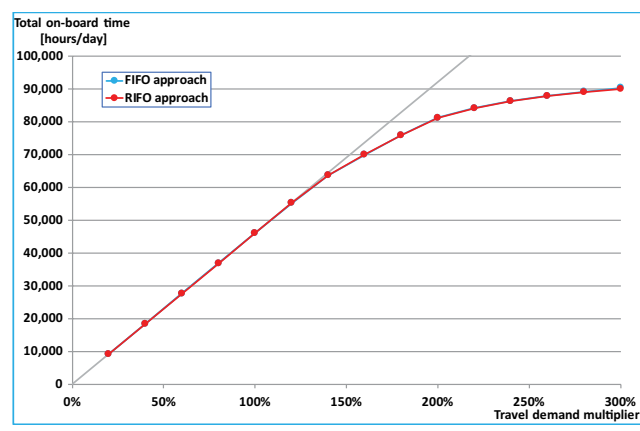

(c)

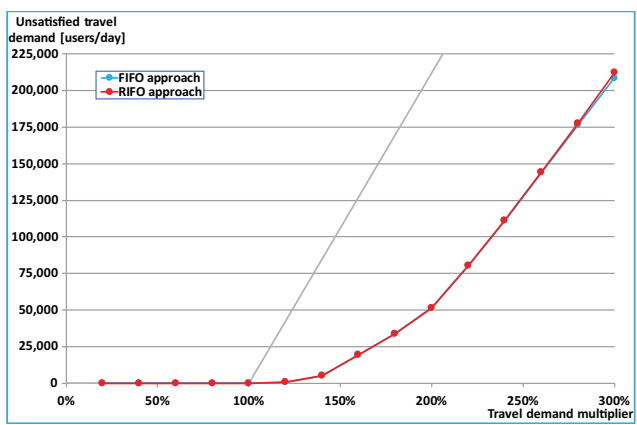

(b)

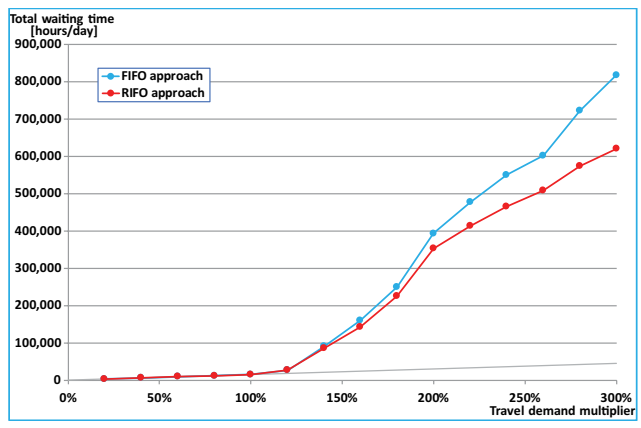

(d)

Figure 4: Simulation results: (a) assigned travel demand; (b) unsatisfied travel demand; (c) Total On-Board Time (TOBT); and (d) Total Waiting Time (TWT). 


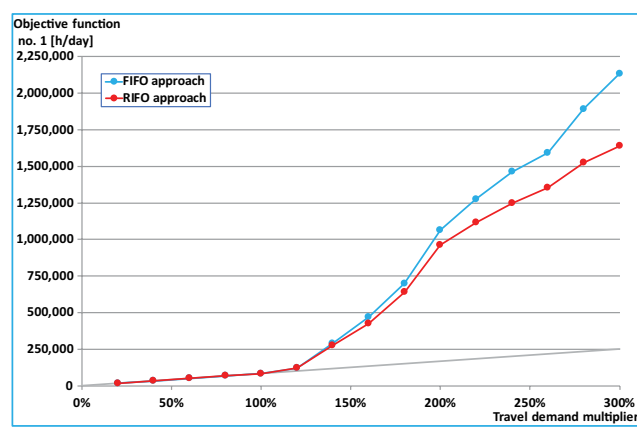

(a)

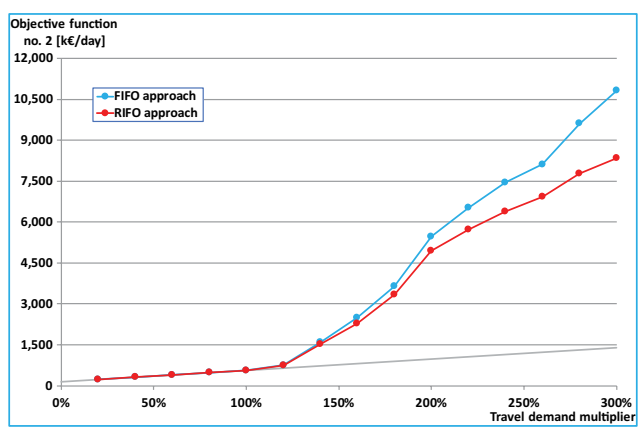

(b)

Figure 5: Values of objective functions: (a) objective function 1 and (b) objective function 2.

In Fig. 4d, the grey line represents the increase in TWT in the case of absence of capacity constraints (i.e. all demand may be assigned on the first arriving train). The limited capacity of convoys (assumption of capacity constraints) means that passengers have to board successive convoys and thus leads to a substantial increase in total waiting time. Moreover, the adoption of different passenger behaviours (i.e. FIFO vs RIFO) profoundly modifies the waiting times. Hence, in this case the increase in travel demand provides great increases in waiting times whose values differ according to the behavioural approach adopted.

In the case of calculation of the objective function, i.e. Fig. 5a and b, where the grey lines represent the objective function being calculated in the absence of capacity constraints, the performance of functions is similar to the total waiting time both in terms of increases and in terms of difference between the two approaches since the TWT term is predominant over others.

\section{CONCLUSIONS AND RESEARCH PROSPECTS}

In this article, we discussed the effect on rail operational simulation in the case of different assumptions on passenger behaviour. In particular, we compared a traditional FIFO approach with an RIFO approach. Initial numerical results showed that the greater the congestion level the greater the difference in results between the two approaches.

In terms of future research, we propose to investigate the difference in results between the two approaches in the case of different fleet compositions (for details, see Ercolani et al. [34], Placido and D'Acierno [35]). Moreover, since in real cases the approaches analysed represent two extreme conditions, future research could explore the use of turnstile data to determine the distribution of passengers who adopt the FIFO approach with respect to those adopting the RIFO approach. Finally, further studies could profitably investigate effects in terms of OD (i.e. origin-destination) matrix estimation (see, for instance, Caropreso et al. [36], Cascetta et al. [37], Di Mauro et al. [38]) by means of flow counts in the event of adopting the two different behavioural approaches.

\section{REFERENCES}

[1] Ben Akiva, M. \& Lerman, S., Discrete Choice Analysis: Theory and Application to Travel Demand. MIT Press: Cambridge, MA, 1985.

[2] Eriksson, L., Garvill, J. \& Nordlund, A.M., Acceptability of single and combined transport policy measures: The importance of environmental and policy specific beliefs. Transportation Research Part A, 42(8), pp. 1117-1128, 2008. DOI: 10.1016/j. tra.2008.03.006. 
[3] Habibian, M. \& Kermanshah, M., Coping with congestion: Understanding the role of simultaneous transportation demand management policies on commuters. Transport Policy, 30, pp. 229-237, 2013. DOI: 10.1016/j.tranpol.2013.09.009.

[4] Meyer, M.D., Demand management as an element of transportation policy: using carrots and sticks to influence travel behaviour. Transportation Research Part A, 33(7-8), pp. 575-599, 1999. DOI: 10.1016/S0965-8564(99)00008-7.

[5] Chien, S. \& Schonfeld, P., Joint optimization of a rail transit line and its feeder bus system. Journal of Advanced Transportation, 32(3), pp. 253-284, 1998. DOI: 10.1002/ atr.5670320302.

[6] Kuan, S.N., Ong, H.L. \& Ng, K.M., Solving the feeder bus network design problem by genetic algorithms and ant colony optimization. Advances in Engineering Software 37(6), pp. 351-359, 2006. DOI: 10.1016/j.advengsoft.2005.10.003.

[7] Shrivastav, P. \& Dhingra, S.L., Development of feeder routes for suburban railway stations using heuristic approach. Journal of Transportation Engineering, 127(4), pp. 334-341, 2001. DOI: 10.1061/(ASCE)0733-947X(2001)127:4(334).

[8] D’Acierno, L., Gallo, M., Montella, B. \& Placido, A., The definition of a model framework for managing rail systems in the case of breakdowns. Proceedings of the 16th IEEE Conference on Intelligent Transportation Systems (ITSC), The Hague, The Netherlands, pp. 1059-1064, 2013. DOI: 10.1109/ITSC.2013.6728372.

[9] Abenoza, R.F., Cats, O. \& Susilo, Y.O., Travel satisfaction with public transport: Determinants, user classes, regional disparities and their evolution. Transportation Research Part A, 95, pp. 64-84, 2017. DOI: 10.1016/j.tra.2016.11.011.

[10] dell'Olio, L., Ibeas, A. \& Cecin, P., The quality of service desired by public transport users. Transport Policy, 18(1), pp. 217-227, 2011. DOI: 10.1016/j.tranpol.2010.08.005.

[11] de Ona, J. \& de Ona, R., Quality of service in public transport based on customer satisfaction surveys: A review and assessment of methodological approaches. Transportation Science, 49(3), pp. 605-622, 2014. DOI: 10.1287/trsc.2014.0544.

[12] Consilvio, A., Di Febbraro, A. \& Sacco, N., Stochastic scheduling approach for predictive risk-based railway maintenance. Proceedings of 2016 IEEE International Conference on Intelligent Rail Transportation (ICIRT), Birmingham, UK, August 2016. DOI: 10.1109/ICIRT.2016.7588732.

[13] Pereira, P., Ribeiro, R.P. \& Gama, J., Failure prediction: An application in the railway industry. Lecture Notes in Computer Science, 8777, pp. 264-275, 2014. DOI: 10.1007/978-3-319-11812-3_23.

[14] Corman, F. \& Meng, L., A review of online dynamic models and algorithms for railway traffic management. IEEE Transactions on Intelligent Transportation Systems, 16(3), pp. 1274-1284, 2015. DOI: 10.1109/TITS.2014.2358392.

[15] Gao, Y., Kroon, L., Schmidt, M. \& Yang, L., Rescheduling a metro line in an overcrowded situation after disruptions. Transportation Research Part B, 93, pp. 425-449, 2016. DOI: 10.1016/j.trb.2016.08.011.

[16] Zhan, S., Zhao, J. \& Peng, Q., Real-time train rescheduling on high-speed railway under partial segment blockages. Journal of the China Railway Society, 38(10), pp. 1-13, 2016. DOI: 10.1016/j.tre.2016.07.015.

[17] Cacchiani, V., Huisman, D., Kidd, M., Kroon, L., Toth, P., Veelenturf, L. \& Wagenaar, J., An overview of recovery models and algorithms for real-time railway rescheduling. Transportation Research Part B, 63, pp. 15-37, 2014. DOI: 10.1016/j.trb.2014.01.009.

[18] Dollevoet, T., Huisman, D., Schmidt, M. \& Schöbel, A., Delay management with rerouting of passengers. Transportation Science, 46(1), pp. 74-89, 2012. DOI: 10.1287/ trsc. 1110.0375 . 
[19] Corman F., D’ Ariano A., Pacciarelli D. \& Pranzo, M., A tabu search algorithm for rerouting trains during rail operations. Transportation Research Part B, 44(1), pp. 175-192, 2010. DOI: $10.1016 /$ j.trb.2009.05.004.

[20] Ghaemi N., Goverde R.M.P. \& Cats O., Railway disruption timetable: Short-turnings in case of complete blockage. Proceedings of 2016 IEEE International Conference on Intelligent Rail Transportation (ICIRT), Birmingham, UK, August 2016. DOI: 10.1109/ ICIRT.2016.7588734.

[21] Montella, B., Gallo, M. \& D’Acierno, L., Multimodal network design problems. Advances in Transport, 5, pp. 405-414, 2000. DOI: 10.2495/UT990381.

[22] D’Acierno L., Placido A., Botte M. \& Montella B., A methodological approach for managing rail disruptions with different perspectives. International Journal of Mathematical Models and Methods in Applied Sciences, 10, pp. 80-86, 2016. http://www. naun.org/main/NAUN/ijmmas/2016/a202001-419.pdf

[23] Botte M., Di Salvo C., Placido A., Montella B. \& D’Acierno L., A neighbourhood search algorithm for determining optimal intervention strategies in the case of metro system failures. International Journal of Transport Development and Integration, 1(1), pp. 63-73, 2017. DOI: 10.2495/TDI-V1-N1-63-73.

[24] Cadarso, L. \& Marìn, A., Improved rapid transit network design model: considering transfer effects. Annals of Operations Research, forthcoming. DOI: 10.1007/s10479015-1999-X.

[25] Lee, Y.J. \& Vuchic, V.R., Transit network design with variable demand. Journal of Transportation Engineering, 131(1), pp. 1-10, 2006. DOI: 10.1061/(ASCE)0733947X(2005)131:1(1).

[26] Marìn, A.G. \& Garcìa-Ròdenas, R., Location of infrastructure in urban railway networks. Computers \& Operations Research, 36(5), pp. 1461-1477, 2009. DOI: 10.1016/j. cor.2008.02.008.

[27] Cantarella, G.E., A general fixed-point approach to multimode multi-user equilibrium assignment with elastic demand. Transportation Science, 31(2), pp. 107-128, 1997. DOI: $10.1287 /$ trsc.31.2.107.

[28] D’Acierno, L., Gallo, M. \& Montella, B., Ant Colony Optimisation approaches for the transportation assignment problem. WIT Transaction on the Built Environment, 111, pp. 37-48, 2010. DOI: 10.2495/UT100041.

[29] Nguyen, S., Pallottino, S. \& Gendreau, M., Implicit enumeration of hyperpaths in a logit model for transit networks. Transportation Science, 32(1), pp. 54-64, 1998. DOI: 10.1287/trsc.32.1.54.

[30] Nuzzolo, A., Russo, F. \& Crisalli, U., A doubly dynamic schedule-based assignment model for transit networks. Transportation Sciences, 35(3), pp. 268-285, 2001. DOI: 10.1287/trsc.35.3.268.10149.

[31] D'Acierno, L., Gallo, M., Montella, B. \& Placido, A., Analysis of the interaction between travel demand and rail capacity constraints. WIT Transactions on the Built Environment, 128, pp. 197-207, 2012. DOI: 10.2495/UT120181.

[32] Kunimatsu, T., Hirai, C. \& Tomii, N., Train timetable evaluation from the viewpoint of passengers by microsimulation of train operation and passenger flow. Electrical Engineering in Japan, 181(4), pp. 51-62, 2012. DOI: 10.1016/j.trb.2007.11.002.

[33] D’Acierno, L., Botte, M., Placido, A., Caropreso, C. \& Montella, B., Methodology for determining dwell times consistent with passenger flows in the case of metro services. Urban Rail Transit, 3(2), pp. 73-89, 2017. DOI: 10.1007/s40864-017-0062-4. 
[34] Ercolani, M., Placido, A., D'Acierno, L. \& Montella, B., The use of microsimulation models for the planning and management of metro systems. WIT Transactions on the Built Environment, 135, pp. 509-521, 2014. DOI: 10.2495/CR140421.

[35] Placido, A. \& D'Acierno, L., A methodology for assessing the feasibility of fleet compositions with dynamic demand. Transportation Research Procedia, 10, pp. 595-604, 2015. DOI: 10.1016/j.trpro.2015.09.013.

[36] Caropreso, C., Di Salvo, C., Botte, M. \& D’Acierno, L., A long term analysis of passenger flows on a regional rail line. International Journal of Transport Development and Integration, 1(3), pp. 329-338, 2017. DOI: 10.2495/TDI-V1-N3-329-338.

[37] Cascetta, E., Papola, A., Marzano, V., Simonelli, F. \& Vitiello, I., Quasi-dynamic estimation of o-d flows from traffic counts: Formulation, statistical validation and performance analysis on real data. Transportation Research Part B, 55, pp. 171-187, 2013. DOI: $10.1016 /$ j.trb.2013.06.007.

[38] Di Mauro, R., Botte, M. \& D’Acierno, L., An analytical methodology for extending passenger counts in a metro system. International Journal of Transport Development and Integration, 1(3), pp. 589-600, 2017. DOI: 10.2495/TDI-V1-N3-589-600. 